\title{
Study on Antidepressant Drug to Cure Depression
}

Naveen Aswal ${ }^{1,2 *}$, Sudhir Kumar Singh ${ }^{3}$ and Praneeth Kamarapu ${ }^{4}$

${ }^{1}$ Department of Pharmacy, Uttrakhand Technical University, Uttarkhand, India

${ }^{2}$ Department of Science, Kumaun University, Almora, India

${ }^{3} B C D A$ College of Pharmacy and Technology Salt Lake City, Kolkata, India

${ }^{4}$ Department of Pharmaceutical Sciences, University of Greenwich, London, UK

\begin{abstract}
Depression is a common mental disorder that present with improper sleep, loss on interest or pleasure including sex, feeling of hopelessness, Low appetite, mood swings and improper concentration and it may occurs in person of all age and gender. Depression may cause various severe physical illnesses like heart stroke, Parkinson, cancer, Diabetes etc. Now a day depression is leading problem which is commonly seen in every second person. According to WHO survey more than 300 million peoples are affected by depression. It may due to family issue, mental, Alcoholism etc. Depression may affect the social behavior of person among the family member and if it is worst it will leads to the suicide. 800,000 people will commit suicide every year due to depression and it is the measure second largest leading cause of death in younger one having age of 18-28. Although there are many treatment therapies for depression but only $10 \%$ peoples will receive such treatment and remaining one either commit suicide or having mental issues including improper sleep, anxiety, anger, Neuro disorders etc. The treatment of depression includes Psychotherapy, Electroconvulsive therapy, Natural alternative and at the last Medication which are explained very well in this article.
\end{abstract}

Keywords: Antidepressants; Depression; Anxiety; Dysthymia; Disorders

\section{Introduction}

Antidepressants are the drug which balances the Chemical imbalance of the Neurotransmitters present in the brain which are responsible for the change in mood and behavior. They are used for a wide range of Psychiatric conditions such as Mild chronic depression also known as dysthymia, Anxiety disorders. Anti-depressants drugs came into existence in 1950s. According to a survey in 1996 there were 13 million people who use anti-depressants in United States and by 2010 it will increase to 21 million. The use of anti-depressants becomes more common because they overcome the situation very easily in case of patient suffering from depression or having any mental illness [1,2].

\section{Types of Depression}

There are following 4 types of depression:

- Major depression

- Dysthymia

- Bipolar disorder/Manic depression

- $\quad$ Seasonal depression (SAD)

- Atypical depression.

\section{Major depression}

Major depression also known as clinical depression is a constant sense of hopelessness and with this condition there is difficult to sleep, work, eat and enjoy with family and friends. Most of cases clinical depression is marked by depressed mood most of the day, mainly at the morning time.

\section{Symptoms include}

- $\quad$ Fatigue

- Feeling of hopelessness

- $\quad$ Restlessness
- Insomnia

- $\quad$ Suicidal thoughts

- Weight loss or gain.

\section{Dysthymia}

Dysthymia also known as mild chronic depression is less severe and has fewer symptoms than major depression. In case of dysthymia the depression may persist for long time of period and hence it is also referred as persistent depressive disorder. Abnormal functioning of nerve cells which connect the different region of the brains regulating mood swings will also involves in depression.

\section{Symptoms}

Same as major depression but are less. Mainly it includes:

- $\quad$ Restlessness

- $\quad$ Fatigue almost every day

- $\quad$ Problems in decision making

- $\quad$ Suicidal attempts.

\section{Bipolar disorder}

Bipolar disorder is also known as manic depression. It is major affective disorder having hippomanic episodes in which someone moods will changes from low to higher energy states. It is complex disorder which may cause due to genetic or non-genetic factors.

*Corresponding author: Naveen Aswal, Department of Pharmacy, Uttrakhand Technical University, Uttarkhand, India, Tel: +91-81262693487; E-mail: nabbu100aswal@gmail.com

Received March 21, 2018; Accepted March 24, 2018; Published March 31, 2018

Citation: Aswal N, Singh SK, Kamarapu P (2018) Study on Antidepressant Drug to Cure Depression. J Formul Sci Bioavailab 2: 121. doi:10.4172/2577-0543.1000121

Copyright: @ 2018 Aswal N, et al. This is an open-access article distributed under the terms of the Creative Commons Attribution License, which permits unrestricted use, distribution, and reproduction in any medium, provided the original author and source are credited. 


\section{Symptoms}

- Hallucinations

- $\quad$ Sleeplessness

- $\quad$ Psychosis.

\section{Seasonal depression (SAD)}

SAD stand for Seasonal affective depression is a type of depression which is related to seasons which mostly seen in spring or early summer season. Treatment of SAD includes psychotherapy, phototherapy and Medications.

\section{Symptoms}

- $\quad$ Feeling guilty, worthlessness

- Low energy

- $\quad$ Interest Losing

- $\quad$ Feeling depressed most of the day.

\section{Atypical depression}

Atypical Depression is subtype of Major depression or Mild chronic depression that having specific symptoms, including weight gain, weakness, fatigue, sensitive to rejections and moods which are extremely reactive to environment circumstances $[3,4]$.

\section{Classification}

Anti-depresent drugs are classified in following 4 categories.

- $\quad$ Selective Serotonin Reuptake inhibitor (SSRIs)

- $\quad$ Monoammino Oxidase Inhibitor (MAOIs)

- $\quad$ Tricyclic Anti-depressants (TCAs)

\section{Tricyclic anti-depressants (TCAs)}

Tricyclic anti-depressants are the largest group of drug which is used for the treatment of the depression. It is referred as Tri-cyclic because it having three ring nucleus. It has high protein binding and high lipid solubility and metabolized in liver.

\section{Drugs classification}

- Doxepim

- Nortryptyline

- $\quad$ Protryptyline

- Amytryptyline

- Desipramine.

Mechanism of action: Tricyclic antidepressants (TCAs) are a group of drugs used to treat affective, or 'mood', disorders. The Mechanism of Action of TCAs drugs is they inhibits the reuptake of the biogenic amines i.e. amines mostly Norephinephrine (NE) and Serotonin (5HT) into the pre synaptic neuron, when there is Neurotransmission takes place between the Pre and Post-synaptic neurons. Despite being an important group of antidepressant drugs they have number of unwanted side effects, which include postural hypotension, due to a adrenoreceptor blockade; sedation, caused by histamine $\mathrm{H} 1$ receptor blockade; and dry mouth, constipation and blurred vision due to muscarinic acetylcholine receptor blockade. The mechanism of action of the drug will be properly understood by the figure below [5,6] (Figure 1).

\section{Structural activity relationship (SAR) of TCAs}

- $\quad$ TCAs basically consist of three rings in which the Centre ring is 7 membered which is linked by 2 benzene rings. Primary or tertiary amine is attached to centre ring.

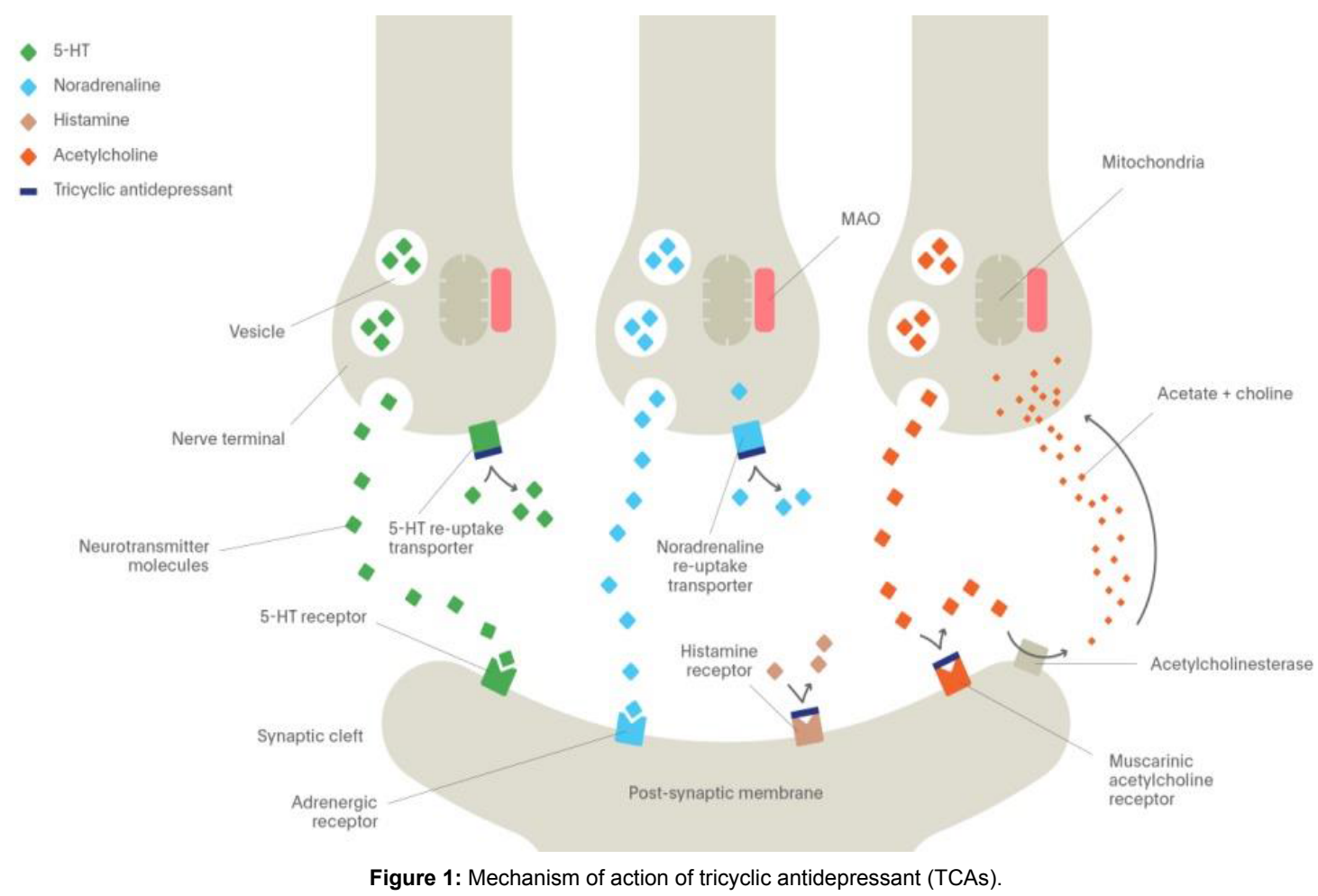


- $\quad$ Substitution of Halogen group or Cyano group i.e. $\mathrm{CN}$ group to the 3 position carbon atom will leads to increase in potency of the drug which increases with the increase in electronegatively of the atom i.e. $\mathrm{F}>\mathrm{Cl}>\mathrm{Br}>\mathrm{I}$.

- $\quad$ Substitution of Dimethyl group or keto-group at $\mathrm{C}_{10}$ position will leads to more effectiveness of the TCAs drugs.

- Substitution of Nitrogen atom with Propylene Bridge in center ring will leads to maximum potency of the drug while the activity will retain if there is replacement of Heterocyclic Nitrogen atom with Carbon atom.

- Introduction of double bond between $\mathrm{C}_{10}$ and $\mathrm{C}_{11}$ will increase the therapeutic effectiveness of the drug.

- Mono amino methyl is more potent than Di amino methyl due to stearic hindrance as shown below in case of Imipramine (2a) and Desimpramine (2b) (Figure 2a and 2b).

Imipramine: Imipramine is the drug which is belongs to the Tricyclic antidepressants class of antidepressant drugs. This medication is used to treat depression and also helps to improve the Appetite, sleep, energy level and mood. It is closely related to the phenothiazine's which is an antipsychotic drug. It is also used in the treatment of Nocturnal enuresis in which the children's having issue of bedwetting during night. Usual dosages form of Imipramine is $50-150 \mathrm{mg}$ daily [7].

Structure<smiles>CN(C)CCCN1c2ccccc2CCc2ccccc21</smiles>

Molecular formula: C19H24N2

Molecular Weight: $280.415 \mathrm{~g} / \mathrm{mol}$.

IUPAC name: 3-(5, 6-dihydrobenzo[b][1]benzazepin-11-yl)-N,Ndimethylpropan-1-amine<smiles>CN(C)CCCN1c2ccccc2CCc2ccccc21</smiles>

Figure 2a: Imipramine.<smiles>CCCN1c2ccccc2CCc2ccccc21</smiles>

Figure 2b: Desimpramine.

\section{Therapeutic use:}

- Dysthymeia treatment

- $\quad$ Agoraphobia

- Bipolar depression

- $\quad$ Anxiety Disorder

- $\quad$ Nocturnal Enuresis

- $\quad$ Schizophrenia.

\section{ADRs}

- $\quad$ Frequent Urination

- $\quad$ Dry mouth

- Constipation

- $\quad$ Blurred Vision

- Drowsiness

- $\quad$ Vomiting

- $\quad$ Mydrasis.

\section{Selective serotonin reuptake inhibitor (SSRIs inhibitors)}

It is the safest antidepressant to use and is a group of chemically unique drug which having high absorption in oral dose. Metabolism will takes place in Liver and excreted through urine and also having longest half-life. Fluoxetine is the first drug under this category and come into use since 1988 (Figure 3).

\section{Drugs include}

- $\quad$ Fluoxetine (Prozac)

- $\quad$ Fluvoxamine (Luvox, Faverin)

- $\quad$ Citalopram (Celexa)

- $\quad$ Escitalopram (Lexapro, Cipralex)

- $\quad$ Sertraline (Zoloft, Lustral)

- $\quad$ Paroxetine (Paxil, Seroxat)

Mechanism of action: The mode of action of SSRIs is it enhances

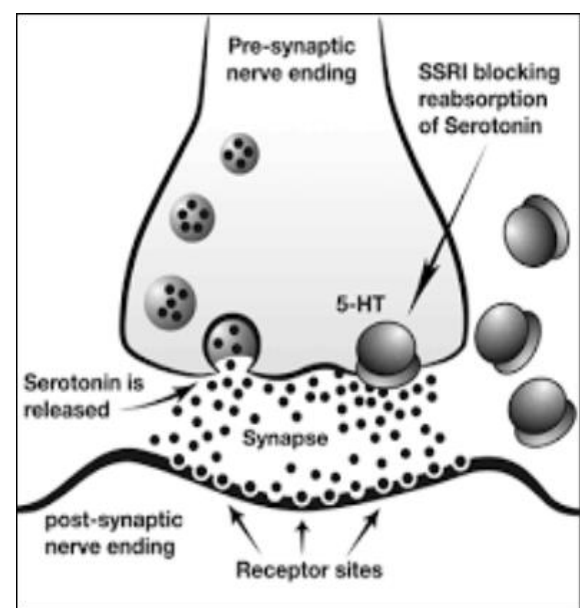

Figure 3: Mechanism of action of SSRIs inhibitor. 
the functioning of the Nerve cell in brain which regulates the emotion, Mood and feelings. Neurotransmitters are the chemical messenger which delivers the signals from one part of the body to another. When there is transfer of signals from the post Synaptic Neuron to the presynaptic neuron with the help of Neurotransmitters than the process is called Neurotransmission and then taking of neurons back to the post synaptic neuron so that they can send the Next message is called Neuron replacement i.e. Reuptake. SSRIs will inhibit the reuptake of the serotonin and hence maintain the level of serotonin into the brain. SSRIs are called to selective one because it mainly targets the Serotonin.

Fluoxetine: Fluoxetine is used in the treatment of depression, panic attack, bulimia and premenstrual syndrome. Fluoxetine mostly helps in the improvement of the appetite, sleep, mood and energy level and also helps in the reduction of unwanted thoughts, fear or any anxiety.

Fluoxetine is helpful in the people feeling to tensed or angry and having repetitive thoughts and behaviors. It helps to feel calm and relaxed. It is available as liquid or in capsule form and also known as Prozac or Sarafem [7] (Figure 4).

Molecular weight: $309.33 \mathrm{~g} / \mathrm{mol}$

Molecular Formula: $\mathrm{C}_{17} \mathrm{H}_{18} \mathrm{~F}_{3} \mathrm{NO}$.

IUPAC name: N-methyl-3-phenyl-3-[4-(trifluoromethyl)phenoxy] propan-1-amine.

\section{Structure:}<smiles>CNCCC(Oc1ccc(C(F)(F)F)cc1)c1ccccc1</smiles>

\section{Therapeutic use}

- $\quad$ Fluoxetine may use in the treatment of several conditions related to mood. It increases the concentration of Neurotransmitter i.e. serotonin between the synaptic cleft.

- Help in the treatment of depression in children's and adult aged 5 to 20 years.

- Help in the treatment of obsessive-compulsive disorder in adult and children aged to 7 to 17 years.

- Helps in the treatment of Agoraphobia, Eating disorder, Bulimia nervosa.

\section{Side effects}

- $\quad$ Dizziness

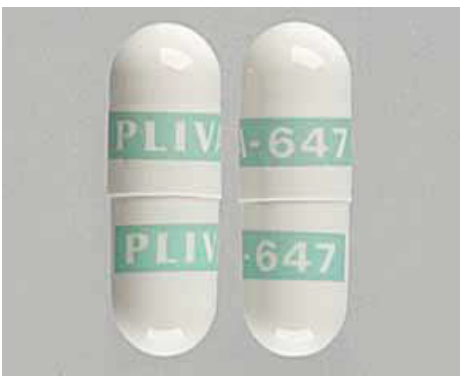

Figure 4: Fluoxetine capsule.
- $\quad$ Sluggish

- $\quad$ Loss of interest in sex

- Headache

- $\quad$ Dry mouth

- $\quad$ Tiredness

- $\quad$ Nausea

- Overdose of Fluoxetine may cause trouble in breathing.

\section{Monoammino oxidase inhibitor (MAOIs)}

Monoammino Oxidase inhibitor is the category of drug which inhibits the activity of both MAO-A and MAO-B enzymes. The use of MAO came into existence for the treatment of depression in 1950's. These are the widely used drugs and having fewer side effects than Tri-cyclic antidepressant. MAOIs increase the level of dopamine, serotonin, Nor-epinephrine neurotransmitter in the brain and helps in the treatment of the depression.

MAOIs drug have high volume of distribution and it is readily absorbed from GI tract. It has an active metabolites which is inactivated by acetylation and also excreted in urine (Figure 5) [8].

\section{Drug classification}

- $\quad$ Phenelzine

- Isocarboxacid

- Tranylcypromine.

Mechanism of action: Mono-amino oxidase enzyme is a mitochondrial enzyme found in nerves and tissues in the body. This enzyme will responsible for the breakdown of neurotransmitter like Serotonin, Norephinephrine and dopamine etc. which leds to major cause of depression. MAO inhibitor drugs will inhibits this enzyme and elevates the level of neurotransmitter in the brain which helps in the cure of depression. It also causes the activation of Serotonin and Norephinephrine receptors which are responsible for the anti-depresent action.

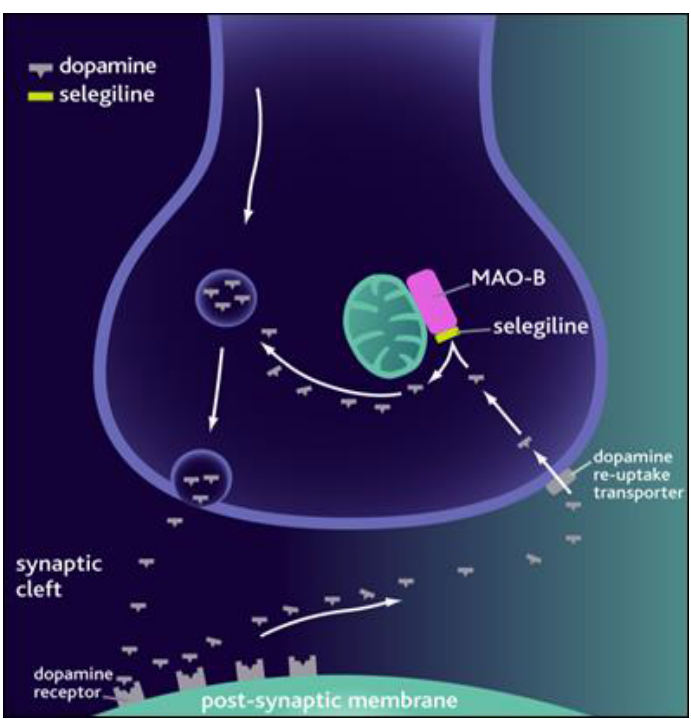

Figure 5: Mechanism of action of MAOls. 
MAO inhibitor reversibly or irreversibly inactivates the enzymes by making a stable complex with the enzymes by which the Neurotransmitters i.e. Dopamine, Serotonin etc. will be accumulated in the synaptic cleft and hence protected from degradation [9].

\section{Phenelzine}

Phenelzine is a Non-selective antidepressant drug which is used for the treatment of depression. Phenelzine is a selected category of drug which having high clinical significance. It is white powder, freely water soluble drug and typically available in $15 \mathrm{mg}$ tablet [10] (Figure 6).

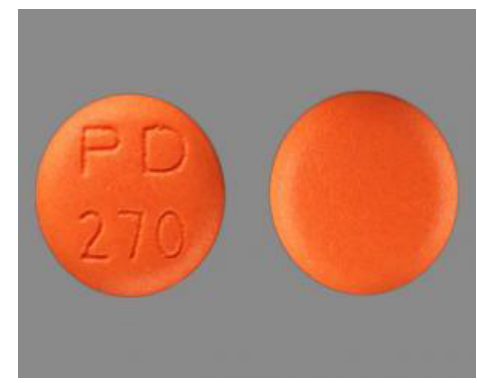

Figure 6: Phenelzine tablet.

\section{Structure}<smiles>NNCCc1ccccc1</smiles>

Molecular Formula: $\mathrm{C}_{8} \mathrm{H}_{12} \mathrm{~N}_{2}$

Molecular Weight: $136.19 \mathrm{~g} / \mathrm{mol}$.

IUPAC Name: 2-Phenylethylhydrazine.

\section{Therapeutic use}

- Heart failure

- Schizophrenia

- Diabetes

- $\quad$ Epilepsy

- Depression.

Adverse effect

- $\quad$ Dizziness

- $\quad$ Blurred Vision

- Hepatitis
- $\quad$ Sexual Disfunctioning

- Muscular Tremors

- $\quad$ Sedation

- Hypotension

- Hyperthermia.

\section{Conclusion}

Depression is major depressive disorder in which feelings of severe despondency and dejection will comes. Antidepressant is the drug which is used to cure the individuals from depression. They having important role in the treatment of depression. It is the lifesaving drug for many individuals in which suicidal thoughts, anxiety, Heart stroke, Parkinson like symptoms will initiates etc. Antidepressant drugs optimize the level of neurotransmitter like Nor-epinephrine, Serotonin, Dopamine in the synaptic cleft due to which the social behavior of a patient will be in control, if he/she is suffering from depression.

The most commonly prescribed class of Drug selective serotonin reuptake inhibitor, or SSRI which includes Prozac, Zoloft, Paxil and Lexapro improves the concentration of Serotonin in brain and carries signals between neurons and helps to regulate mood. SSRI have been helpful for many individuals and they are very efficient drug to cure the depression in earlier stage.

\section{References}

1. Stahl SM, Grady MM (2003) Differences in mechanism of action between current and future. The Journal of Clinical Psychiatry 13: 13-17.

2. http://theantidepressants.blogspot.com/2009/03/introduction-toantidepressant-drugs.html

3. Morin A (2018) 4 Types of Depression Commonly Found in Teens. Verywell mind.

4. Kerr GW, McGuffie AC, Wilkie S (1959) Tricyclic antidepressant overdose: a review. BMJ Journals Vol: 8.

5. Gillman PK (2007) Tricyclic antidepressant pharmacology and therapeutic drug interactions updated. British Journal of Pharmacology 151: 737-748.

6. Schaik NV, Graf U (1993) Structure-activity relationships of tricyclic antidepressants and related compounds in the wing somatic mutation and recombination test of Drosophila melanogaster. Mutation Research/ Fundamental and Molecular Mechanisms of Mutagenesis 286: 155-163.

7. Selective serotonin reuptake inhibitors (SSRIs) by Mayo clinic staff.

8. Harfenist M, Joseph MD, Spence SC, Mcgee PCD, Reeves MD, et al (1997) Selective Inhibitors of Monoamine Oxidase. 4.1 SAR of Tricyclic N-Methylcarboxamides and Congeners Binding at the Tricyclics' Hydrophilic Binding Site. J Med Chem 40: 2466-2473.

9. Nakamura K, Masuda Y, Tatsumi H, Fujimoto K (1963) Structure And Activity Relationship Of Monoamine Oxidase Inhibitors, Phenylacetylhydrazide Derivatives The Japanese Journal of pharmacology 13: 186-194.

10. Fiedorowicz JG, Swartz KL (2004) The Role of Monoamine Oxidase Inhibitors in Current Psychiatric Practice. Journal of Psychiatric Practice 10: 239-248. 